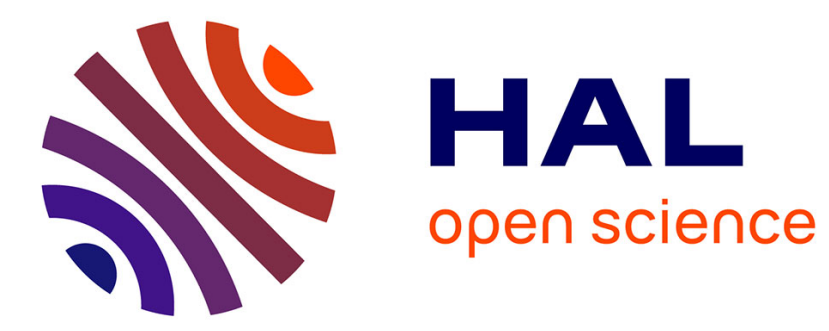

\title{
On the early stages of wind-wave generation under accelerated wind conditions
}

Lucia Robles-Diaz, Francisco Ocampo-Torres, Hubert Branger, Hector

Garcia-Nava, Pedro Osuna, Nicolas Rascle

\section{- To cite this version:}

Lucia Robles-Diaz, Francisco Ocampo-Torres, Hubert Branger, Hector Garcia-Nava, Pedro Osuna, et al.. On the early stages of wind-wave generation under accelerated wind conditions. European Journal of Mechanics - B/Fluids, 2019, 78, pp.106-114. 10.1016/j.euromechflu.2019.06.007 • hal-02181844

\section{HAL Id: hal-02181844 \\ https://hal.science/hal-02181844}

Submitted on 12 Jul 2019

HAL is a multi-disciplinary open access archive for the deposit and dissemination of scientific research documents, whether they are published or not. The documents may come from teaching and research institutions in France or abroad, or from public or private research centers.
L'archive ouverte pluridisciplinaire HAL, est destinée au dépôt et à la diffusion de documents scientifiques de niveau recherche, publiés ou non, émanant des établissements d'enseignement et de recherche français ou étrangers, des laboratoires publics ou privés. 


\title{
On the early stages of wind-wave generation under accelerated wind conditions
}

\author{
Lucia Robles-Diaz ${ }^{\mathrm{a}, *}$, Francisco J. Ocampo-Torres ${ }^{\mathrm{a}}$, Hubert Branger ${ }^{\mathrm{b}}$, \\ Hector Garcia-Nava ${ }^{c}$, Pedro Osuna ${ }^{a}$, Nicolas Rascle ${ }^{a}$ \\ a Departamento de Oceanografía Física, Centro de Investigación Científica y de Educación Superior de Ensenada, Ensenada, Mexico \\ ${ }^{\mathrm{b}}$ Aix-Marseille Univ, CNRS, Centrale Marseille, IRPHE, Marseille, France \\ ${ }^{\mathrm{c}}$ Instituto de Investigaciones Oceanológicas, Universidad Autónoma de Baja California, Ensenada, Mexico
}

\section{A R T I C L E I N F O}

\section{Article history:}

Received 17 November 2018

Received in revised form 11 June 2019

Accepted 12 June 2019

Available online 14 June 2019

\section{Keywords:}

Drag coefficient

Accelerated wind

Incipient wave generation

\begin{abstract}
A B S T R A C T
The energy and momentum transfer between the atmosphere and the ocean has typically been studied for conditions where the waves have almost or already reached a local equilibrium with a uniform wind. The purpose of this work is to investigate the early stages of the generation of waves under non-stationary wind conditions and to describe the momentum and energy exchange at the airwater interface for non-equilibrium wind conditions. Some experiments with a characteristic wind acceleration were conducted in a large wind-wave facility at the Institut Pythéas (Marseille-France). Momentum fluxes were estimated through hot-wire anemometry and, the free surface displacement was measured along the wave tank by resistance and capacitance wire probes. Wind speed and water elevation measurements were acquired at a high sampling rate. During the experiments, the wind speed was increased with a constant acceleration over time, reaching a constant maximum intensity of $13 \mathrm{~ms}^{-1}$. Under accelerated wind conditions, the degree of wave field development associated with a certain value of wind speed depends on the wind acceleration. Accordingly, once the rough flow regime is established, the drag coefficient values associated with a certain wind speed also vary depending on wind acceleration. It was observed that higher wind speed is needed to reach a rough flow regime as the wind acceleration increases. Also, the momentum transfer is reduced as wind acceleration increases. Under the rough flow regime, a less developed wave field induces a higher increase of drag coefficient with wind speed.
\end{abstract}

(c) 2019 Published by Elsevier Masson SAS.

\section{Introduction}

Momentum is one of the most significant quantities considered for a correct description of the coupling processes between the ocean and the atmosphere. Due to the continuity of the momentum flux across the air-sea interface, it is necessary to have a correct description of air-side stress to estimate the waterside stress and the momentum flux radiated out by propagating surface waves. Moreover, ocean waves create a mobile interface that can modify air-sea fluxes of momentum, kinetic energy, heat, gas, and other constituents. Air-sea fluxes are known to be sea state dependent, and the surface waves also modify the airflow turbulence and wind-temperature-humidity profiles as compared with those over a flat surface [1,2].

Momentum transfer is usually characterized through the drag coefficient, $C_{\mathrm{D}}$. The drag coefficient, measured at a given height $z$, is defined by the ratio $C_{D}=u_{*}^{2} / U^{2}$, where $u_{*}$ is the friction

\footnotetext{
* Corresponding author.

E-mail address: Irobles@cicese.edu.mx (L. Robles-Diaz).
}

velocity and $U$ the wind speed measured at height $z . C_{D}$ is usually denoted $C_{D_{10}}$ when the reference height is $z=10 \mathrm{~m}$. Many parametrizations of $C_{D_{10}}$ as a function of wind speed can be found in the literature [3-6]. However, its dependency on wind speed still presents remarkable scatter between different experimental studies. Besides, [7] found that gustiness was responsible for the most distant outliers in drag coefficient values. Also, several studies have shown the influence of the sea state on surface roughness and drag coefficient behaviour [e.g.1,2,8,9]. However, determining the dependence of sea-surface drag on sea state remains a core focus of wind-wave research [10,11]. For the description of the evolution of sea states, it is common to use the significant wave height and the dominant frequency. Several authors present empirical growth functions that describe the development of the wave field under uniform wind conditions [e.g.12,13]. Other authors show that even when the waves are growing, they are in local equilibrium with wind [14,15]. A more recent study discusses the process of energy redistribution by nonlinear interactions during the first stages of wind waves generation in an annular wave flume [16]. The wave field statistics during the early 
stages of wave growth were found to be close to a corresponding Gaussian regime and, the maximum deviation from this regime was detected just before the stationary stage was reached. This highlights the relevance of the early stages of wave generation at least within the context of potential characteristics to favour rogue wave development.

Most of the studies of wind-waves generation focus on uniform and stationary wind speeds. However, in the open field, it is common to have conditions of wind blowing with a characteristic acceleration before a constant wind condition is reached. Moreover, there are situations with accelerated extreme wind conditions that may be maintained several hours and reach wind speed up to $20 \mathrm{~m} \mathrm{~s}^{-1}$. Two well-known examples of wind wave fields generated under accelerated wind conditions are the ones associated with Tehuano winds (Gulf of Tehuantepec, Mexico [17]) and Mistral winds (Gulf of Lyon, France [18]). Furthermore, the track and intensity forecast of tropical cyclones requires detailed knowledge of the air-sea interface fluxes also under accelerated wind conditions.

Laboratory experiments showed that under nonstationary wind conditions (accelerating and decelerating winds), the delayed adjustment of the wind-waves produces variations in the wind stress values associated with a certain wind speed [19]. [20] showed that after an abrupt wind increase, the adjustment between the waves and the airflow takes place at two different time-scales, one being determined by the local equilibrium and the other one by the fetch.

There is a remarkable need to study the initial stages of windwave generation and evolution under accelerated wind conditions. For this sake, a set of experiments were carried out in a large wind-wave facility. Several runs were performed to provide a wide range of wind conditions and wave development stages under different wind accelerations. High temporal resolution devices were employed to provide a detailed characterization of the air boundary layer and free surface displacement.

The primary objective of this experimental study is to describe the development of the air-turbulent boundary layer and to determine the momentum exchange under different scenarios of accelerated wind conditions. Besides, it is aimed to describe the effect of wind waves on the drag coefficient evolution. The experimental design, the facilities, and the equipment used, as well as the data processing, are presented in Section 2. The analysis of the air-turbulent boundary layer evolution and a description of the behaviour of the drag coefficient under non-stationary wind conditions are explained in Section 3. The main results regarding wave growth in non-dimensional terms are given in Section 4 and a summary in Section 5.

\section{Experimental design and basic data processing}

\subsection{Facility and measuring devices}

The experiments were conducted in the Aix-Marseille Universitè Institut Pythéas wind-wave facility in Marseille, France. The wave tank is $40 \mathrm{~m}$ long, $2.6 \mathrm{~m}$ wide and $1 \mathrm{~m}$ deep. The air section is $50 \mathrm{~m}$ long, $3 \mathrm{~m}$ wide, and $1.6 \mathrm{~m}$ high (Fig. 1). A complete description of the facility can be found in [21], and the facility is also described at http://www.pytheas.univ-amu.fr/?LASIF-Grande-Soufflerie-air-eau-de-Luminy-.

This air-sea interaction facility is a closed-loop flume, with a combined action of air-sucking and air-pumping all along the facility. This system minimizes the spatial variations of wind speed along the flume in comparison with an open-loop facility and makes it more suitable to carry out experiments of wave generation under accelerated wind conditions. The wind is generated by a fan located within the air re-circulation duct at the top of the flume. Also, the height of the wind tunnel changes along the tunnel to maintain the airflow boundary layer with constant momentum flux adjacent to the water [22]. At the downwind end of the tank, a dissipative beach is located to minimize wave reflection. The desired wind speed variations in time were controlled with a computer under a coupled Matlab/Labview real-time control software that allows us to reproduce the same wind conditions several times. This computer system is a handy tool for repeating the experiments and increasing the statistical significance of the results.

The experimental set-up included 11 water elevation measuring stations where the shortest and largest fetches were 1.01 and $30.73 \mathrm{~m}$, respectively. Mean and turbulent flow characteristics were measured at station 7 using two thermal anemometers. The first one was a single-sensor miniature hot wire probe (Dantec Dynamics 55P11 length $1.25 \mathrm{~mm}$, diameter $5 \mu \mathrm{m}$ ) used to measure the mean wind speed at an acquisition frequency of $256 \mathrm{~Hz}$, and installed at $72.0 \mathrm{~cm}$ above the mean water surface. This constant-temperature hot wire has a high-frequency response of $512 \mathrm{~Hz}$ and can measure precisely wind fluctuations. It was calibrated using a Pitot tube through the determination of King's law, $V^{2}=a+b\left(U_{\text {ref }}\right)^{1 / 2}$, where $V$ is the anemometer output voltage, $U_{\text {ref }}$ is the wind velocity obtained from the Pitot tube and $a$ and $b$ are coefficients to be found [23]. The Pitot tube was also located at station 7 , at $72.0 \mathrm{~cm}$ above the mean water surface. This height is half the facility air section, and it is always above the wave-induced turbulent air flow. The wind speed measured at this location is taken as reference. The other anemometer was a miniature $\mathrm{X}$ wire probe, (Dantec Dynamics 55P61 length $1.25 \mathrm{~mm}$, diameter $5 \mu \mathrm{m}$ ) combined with a Streamline anemometry system software (Dantec Dynamics). This $\mathrm{X}$ wire probe was used to determine directly the total wind stress, $\tau=\rho u_{*}^{2}=-\rho\left(\overline{u^{\prime} w^{\prime}}\right)$, over the water surface through the eddycovariance method [24], where $\rho$ is the air density and $u^{\prime}$ and $w^{\prime}$ are the horizontal and vertical turbulent component of wind speed, respectively. The $\mathrm{X}$ wire probe was installed in station 7 at $14.5 \mathrm{~cm}$ above the mean water surface, and it measures $u$ and $w$, the horizontal and vertical component of wind velocity, respectively, at a high-frequency rate of $256 \mathrm{~Hz}$. The $\mathrm{X}$ wire probe was calibrated using the Dantec StreamLine Pro Calibrator unit. During the calibration, the $\mathrm{X}$ wire probe is placed at the jet exit, and the pitch-yaw manipulator allows the 2D probe to be rotated for calibration of directional sensitivity (see Dantec publication No.: 238v12 "Probes for hot-wire anemometry"). Due to facility limitations, only station 7 is provided with the required infrastructure to install the thermal anemometers.

Resistance wire probes from the DHI company were installed at all stations along the water channel to measure the instantaneous surface elevation, $\eta(t)$. The resistance wires present a $0.5 \mathrm{~mm}$ resolution and a $20 \mathrm{~Hz}$ frequency response. Additionally, capacitance wire probes from DISA company were installed at the most relevant positions (stations 1, 2 and 7), at the beginning of the tank for the incoming conditions, and at station 7, where most of the measurements were done. The capacitance wire probes present higher resolution and frequency response than resistance wire probes $(0.1 \mathrm{~mm}$ and $70 \mathrm{~Hz}$, respectively). The sampling frequency for water surface displacement was $256 \mathrm{~Hz}$, the same used for the thermal anemometers.

Previous experiments conducted in this facility showed the existence of a constant vertical stress layer within the first $0.15 \mathrm{~m}$ above the water surface and found that the precision of the stress measurements within this layer was of the order of $10 \%$ [22]. 


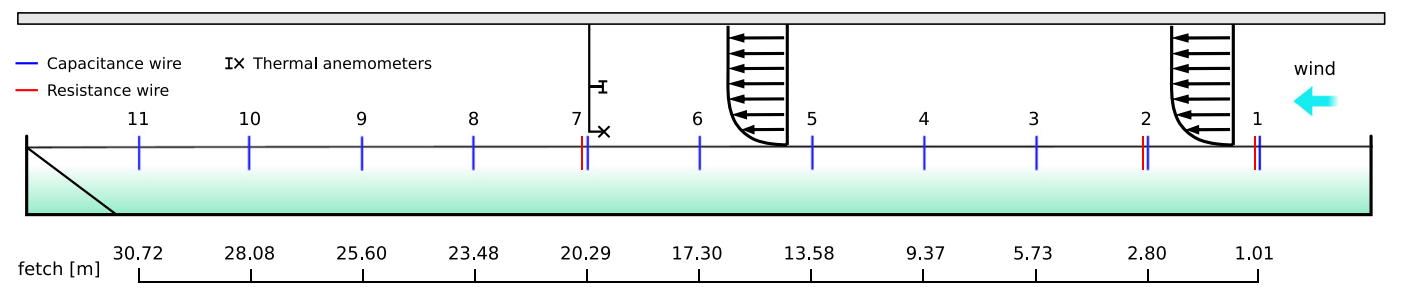

Fig. 1. Layout of the Institut Pythéas wind-wave facility (not to scale), where the measuring station locations are depicted.

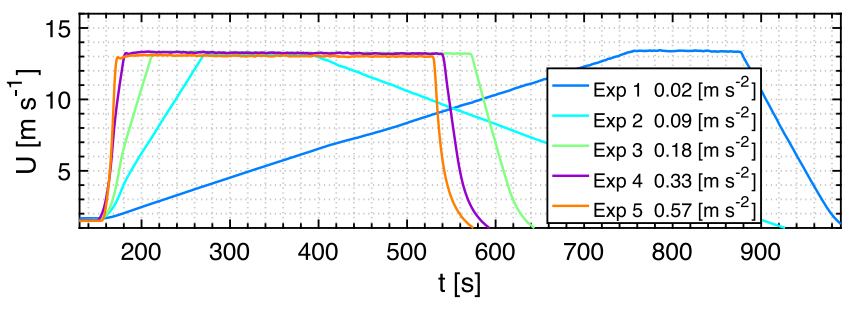

Fig. 2. Temporal variation of mean wind speed, $U$, during the experiments. Colours denote constant acceleration values characteristic of each experiment.

\subsection{Experimental runs}

The wind speed history of the 5 experiments being analysed in this work is presented in Fig. 2. Each experiment has a specific wind acceleration. In the initial part of each experiment, the wind intensity was rather low, around $1 \mathrm{~m} \mathrm{~s}^{-1}$, and it was kept approximately constant for about 2 to $3 \mathrm{~min}$. This period is intended to check that all the devices are measuring correctly before the acceleration part starts. Subsequently, wind intensity was increased with a constant acceleration, reaching a mean wind speed of $13 \mathrm{~m} \mathrm{~s}^{-1}$. After that, a constant wind speed was maintained, from 2 to 7 min depending on the experiment, until a constant deceleration phase was imposed to complete the experimental run. All the results shown below belong to the period of constant wind acceleration.

The period with constant wind speed was used to characterize the equilibrium state between wind and waves under steady and maximum wind speed. As it was said previously, the time history of wind variations was controlled with real-time controlcommand software, so it was possible to repeat each experiment several times. Each experiment was repeated 3 times. However, because the $\mathrm{X}$ wire probe failed during several experiments, only the complete data set of the three replicates for experiment 7 is available and shown in the present work. The data were analysed to get information about the state of development of the air boundary layer and the generation and evolution of the wave field under constant acceleration wind conditions.

\subsection{Basic data processing}

The temporal evolution of the turbulent components of wind speed that were measured, $u^{\prime}$ and $w^{\prime}$, and its product, $u^{\prime} w^{\prime}$ for the experiment 1 is shown in Fig. 3. It can be observed that during the acceleration phase, the turbulent fluctuations increase with the wind speed. This experiment, with the lowest acceleration, presents the highest magnitude of $u^{\prime}, w^{\prime}$ and $u^{\prime} w^{\prime}$, while as the acceleration increases for the different experimental runs preformed, the magnitude of $u^{\prime}, w^{\prime}$ and $u w^{\prime}$ decreases (not shown).

For each experiment, co-spectra, $S_{u w}$, and normalized cumulative co-spectra, between the vertical and horizontal wind components, were estimated to examine the relative importance of the energy of the frequencies resolved in the measurements and, to focus on the physical processes of interest. Time covariance
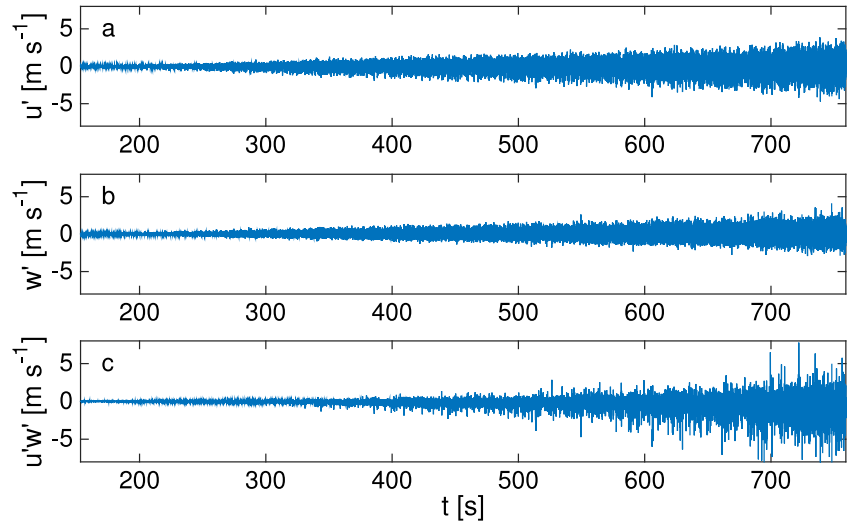

Fig. 3. Time series of the turbulent components of wind speed, (a) $u^{\prime}$ and (b) $w^{\prime}$ and (c) the product $u^{\prime} w^{\prime}$, for experiment 1 during the wind acceleration phase
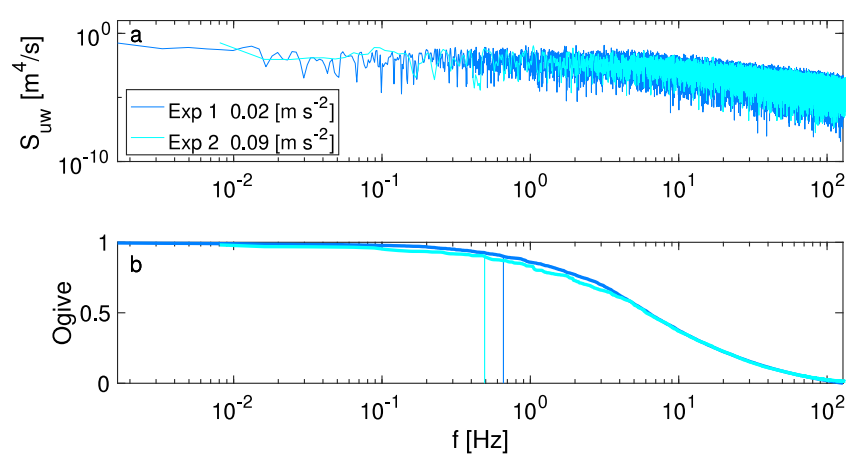

Fig. 4. (a) Co-spectra of fluctuating component of wind velocity, $S_{u w}$, and (b) normalized cumulative co-spectra, as a function of frequency, $f$, for experiments 1 and 2. Vertical lines indicate the frequency at which $90 \%$ of the cumulative energy is reached in each experiment.

procedures were used to determine the suitable temporal windows to apply the eddy covariance method, assuring that most of the characteristic frequencies were included in the analysis. From this analysis, it was suitable to establish that $2 \mathrm{~s}$ duration sliding window was statistically sufficient to estimate $\overline{u^{\prime} w^{\prime}}$ because $90 \%$ of the cumulative co-spectra is obtained within this time-interval (Fig. 4).

The effect of increasing the duration of the sliding window in the determination of $u_{*}$ through the eddy covariance method, it was analysed. It was confirmed that a $2 \mathrm{~s}$ moving window is suitable for the friction velocity estimation because it still keeps the original variability of the time series.

Because the accelerated wind conditions represent the focus of study in the present work, measured mean wind speed, $U, 10$ m reference wind speed, $U_{10}$, and friction velocity, $u_{*}$ are shown in Fig. 5, for the accelerated phase of experiments 1 to 5 . The $U_{10}$ was estimated, assuming neutral conditions and a logarithmic wind profile, through the expression $U_{10}=U+\left(u_{*} / \kappa\right) \ln \left(10 / z_{\text {ref }}\right)$, 

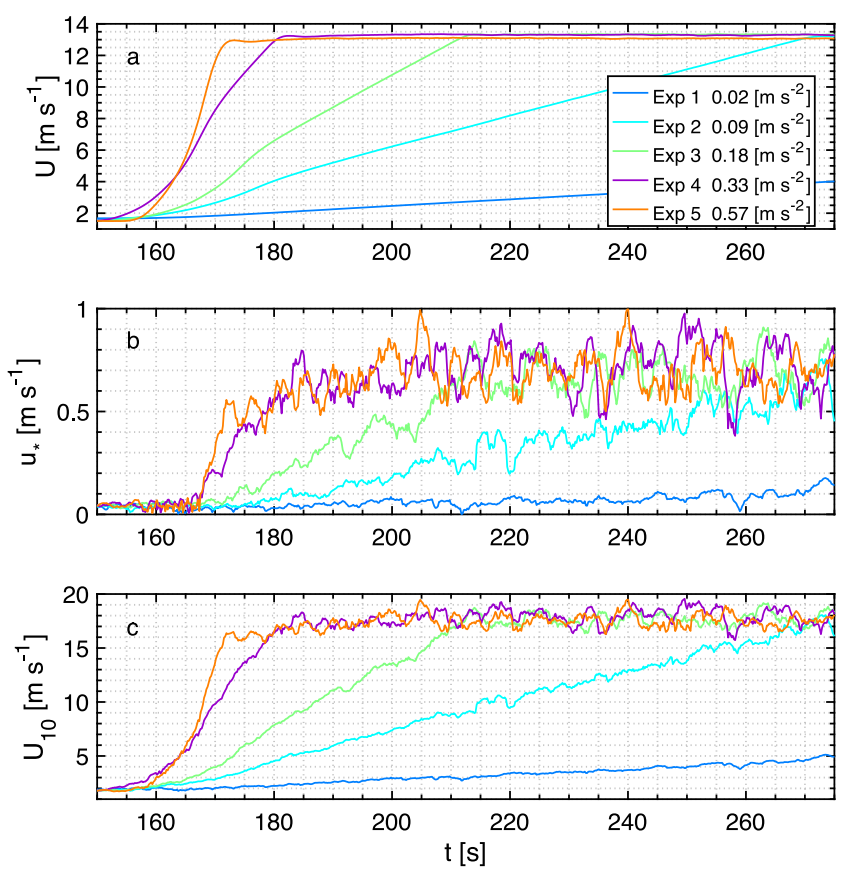

Fig. 5. Temporal variation of (a) mean reference wind speed, $U$, (b) friction velocity, $u_{*}$ and (c) $10 \mathrm{~m}$ reference wind speed, $U_{10}$, during the accelerated wind conditions of each experiment.

where $z_{\text {ref }}$ is the height where the single anemometer was located and $\kappa$ is the Von Kármán constant. The results associated with the experiment with the lowest acceleration are not shown completely to provide a more comprehensive view of the variable changes associated with the other experiments during the acceleration period. $U_{10}$ is used as the reference velocity to compare drag coefficient results with previous parametrizations. $u_{*}$ is typically used to express some wave field variables in a nondimensional form, including those used as a reference in wave growth studies.

In Fig. 5, it can be observed that $u_{*}$ reached different values at the end of the acceleration period, depending on the experiment. Experiment 3 is the one that reaches the maximum value of $u_{*}$ at the end of the acceleration period (experiment 1 reached $0.62 \mathrm{~m} \mathrm{~s}^{-1}$, not shown). The friction velocity also presents some fluctuations during the acceleration period that differs from one experiment to another, and it is a direct indicator that the air boundary layer evolves in a different way depending on the wind acceleration.

\section{Air boundary layer}

The evolution of $u_{*}$ as a function of wind speed, $U_{10}$, is presented in Fig. 6a. It is observed that the friction velocity increases with wind speed. Despite all the experiments reach the maximum wind speed, the friction velocity associated with this wind speed differs between experiments. Experiment 3 shows the highest magnitude of $u_{*}$ associated with the maximum wind speed.

Another significant variable of the air boundary layer is the viscous sublayer thickness, $z_{f}=v_{\text {air }} / u_{*}$, where $v_{\text {air }}$ is the air kinematic viscosity. This variable represents the distance from the surface at which the transition between the viscous sublayer and the inertial sublayer occurs. In the viscous sublayer, the effect of friction is dominant, and the viscosity plays a significant role [25]. The results show that, for given wind speed, the viscous sublayer is thicker for high acceleration experiments, as it can be readily apparent in Fig. 6b. There, it is also observed that the viscous
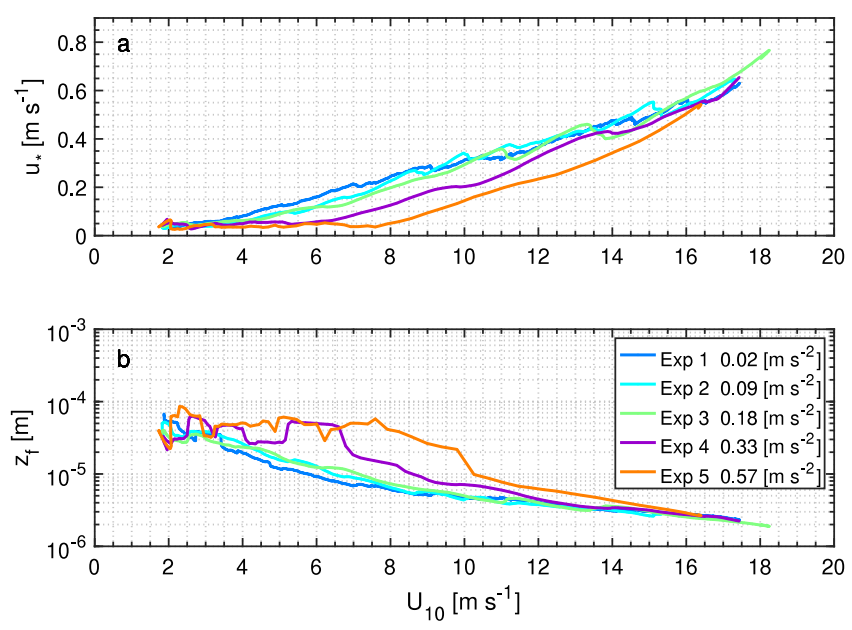

Fig. 6. (a) Friction velocity, $u_{*}$, (b) thickness of the viscous sublayer, $z_{f}$ and (c) roughness length, $z_{0}$ versus $10 \mathrm{~m}$ reference wind speed, $U_{10}$.

sublayer becomes thinner as the wind speed increases. These experimental results indicate that for high wind acceleration experiments, the roughness elements at the surface need to be higher to protrude the viscous sublayer and to have a direct influence on the airflow within the boundary layer.

Also, the roughness length, $z_{0}$, was estimated to compare its order of magnitude with $z_{f}$ (not shown). The roughness length gives an idea of the size of the roughness elements. $z_{0}$ was estimated from the following relation, assuming the existence of a logarithmic wind profile, $z_{0}=10 / e^{\left(\kappa / \sqrt{C_{D_{10}}}\right)}$. The $z_{f}$ and $z_{0}$ have the same order of magnitude $\left(10^{-4} \mathrm{~m}\right)$. When $z_{0}>z_{f}$, the roughness elements protrude the viscous sublayer and have a direct effect in increasing the turbulence in air flow. In Table 1 the values of $U_{10}$ associated with the $z_{f}=z_{0}$ threshold are given.

It is important to define the specific requirements for the establishment of a rough flow regime, to study the wind stress associated with the development of the air boundary layer. The rough flow regime is established when the shear stress is dominated by the drag of the roughness elements as compared to smooth flow when the shear stress is governed by viscosity. The transition between smooth and rough flow regimes over water surfaces was previously characterized by several authors [26,27]. To define this transition, the roughness Reynolds number, $R e_{*}=$ $u_{*} z_{0} / v_{\text {air }}$, has been used. The flow regime is smooth when $R e_{*}<$ 0.13 , and it is rough when $R e_{*}>2.2$.

The roughness Reynolds number, $R e_{*}$, was calculated to characterize the air-flow behaviour and to determine if the surface roughness influences the air flow, i.e., to establish when the transition from smooth to rough regime occurs, and when generated waves in the water surface influence the wind stress behaviour. The $R e_{*}$ as a function of wind speed, $U_{10}$, computed at station 7 at a fetch of $20.29 \mathrm{~m}$, is shown in Fig. 7. During each experimental run, low wind speed is associated with a smooth flow regime with $R e_{*}<0.13$. Under this regime, the tendency of $R e_{*}$ is to decrease as the wind speed increases. It was observed that, exceeding a threshold, higher wind speed induces an increase of $R e_{*}$ with the wind, depending on each experiment (hence the wind acceleration). This velocity threshold varies from 3 to $9 \mathrm{~m} \mathrm{~s}^{-1}$ for experiment 1 to 5 , respectively. The lowest values of $R e_{*}$ occurred during the two experiments with the highest accelerations. In those experiments, large fluctuations of $R e_{*}$ are detected under the lowest wind speed period at the beginning of the runs. In contrast, $R e_{*}$ values seem to keep a positive trend with increasing $U_{10}$, in the experiments with the lowest acceleration (Fig. 7). 


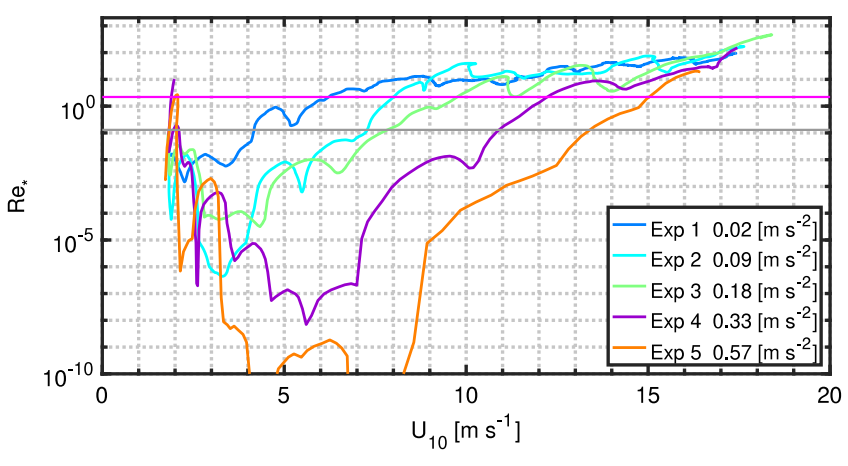

Fig. 7. Roughness Reynolds number $\left(R e_{*}\right)$ as a function of $10 \mathrm{~m}$ reference wind speed, $U_{10}$. Horizontal grey and magenta lines indicate the $R e_{*}$ value associated with the limit for smooth flow regime $\left(R e_{*}<0.13\right)$ and the threshold to reach a fully rough flow regime $\left(R e_{*}>2.2\right)$, respectively. (For interpretation of the references to colour in this figure legend, the reader is referred to the web version of this article.)

\section{Table 1}

Results from each experiment for the reference wind speed, $U_{10}$, and friction velocity, $u_{*}$, of encounter, to match the limit $R e_{*}<0.13$, to reach the threshold $R e_{*}>2.2$, and for $z_{f}=z_{0}$.

\begin{tabular}{lllllll}
\hline Exp. & $U_{10_{\text {tran. }}}$ & $U_{10 z_{f}=z_{0}}$ & $U_{10_{\text {rough }}}$ & $u_{* \text { tran. }}$ & $u_{* z_{f}=z_{0}}$ & $u_{*_{\text {rough }}}$ \\
\hline & {$\left[\mathrm{m} \mathrm{s}^{-1}\right]$} & {$\left[\mathrm{m} \mathrm{s}^{-1}\right]$} & {$\left[\mathrm{m} \mathrm{s}^{-1}\right]$} & {$\left[\mathrm{m} \mathrm{s}^{-1}\right]$} & {$\left[\mathrm{m} \mathrm{s}^{-1}\right]$} & {$\left[\mathrm{m} \mathrm{s}^{-1}\right]$} \\
\hline 1 & 4.17 & 9.69 & 6.22 & 0.09 & 0.29 & 0.17 \\
2 & 7.29 & 7.94 & 8.01 & 0.17 & 0.22 & 0.23 \\
3 & 7.84 & 14.06 & 9.74 & 0.19 & 0.40 & 0.27 \\
4 & 10.85 & 12.18 & 12.18 & 0.24 & 0.34 & 0.34 \\
5 & 13.53 & 14.74 & 14.95 & 0.31 & 0.39 & 0.40 \\
\hline
\end{tabular}

The reference wind speed, $U_{10}$, and friction velocity, $u_{*}$, at which the smooth flow regime limit is reached $\left(U_{10_{\text {tran. }}}\right.$ and $u_{* \text { tran. }}$, respectively) and at which rough flow regime is established $\left(U_{10_{\text {rough }}}\right.$ and $u_{*_{\text {rough }}}$, respectively) are shown in Table 1 . The reference wind speed $U_{10}$, and friction velocity, $u_{*}$, corresponding to $z_{f}=z_{0}$ is also given. In general terms, the lower the wind acceleration, the lower wind speed required to reach the smooth flow regime limit, as well as to reach the rough flow regime threshold.

The direct estimation of the wind stress $\left(\tau=-\rho\left(\overline{u^{\prime} w^{\prime}}\right)\right)$ is possible through the eddy covariance method, taking advantage of the relatively high sampling rate and fast response of the $\mathrm{X}$ wire probe. From these direct measurements of the total stress, it is possible to determine the behaviour of the drag coefficient, making use of a $2 \mathrm{~s}$ moving window for the covariance method procedure. The variation of the $C_{D_{10}}$ as a function of $U_{10}$ is shown in Fig. 8, as bin average with a class interval equal to $1 \mathrm{~m} \mathrm{~s}^{-1}$ in the wind speed. The bars indicate \pm standard deviation of $C_{D_{10}}$, within each class. The circles and asterisks symbols marked the resulting values for $C_{D_{10}}$ encountered at the limit for smooth flow regime and the threshold for rough flow regime, respectively (also given in Table 2). They were determined through the $U_{10}$ associated with $R e_{*}$ threshold shown in Table 1.

Under smooth flow regime, it is readily apparent that $C_{D_{10}}$ decreases with the wind speed in every experiment, from low wind speed to a particular speed that depends on the specific run (except in experiment 1 , that does not present a decreasing tendency). Therefore, a relative minimum in $C_{D_{10}}$ is attained for wind speeds within the interval $3 \mathrm{~m} \mathrm{~s}^{-1}<U_{10}<9 \mathrm{~m} \mathrm{~s}^{-1}$. For relatively higher winds, $C_{\mathrm{D}_{10}}$ increases with the wind, under conditions where the transition flow regime has not been reached. Under the transition regime, the increasing tendency of $C_{D_{10}}$ with wind speed is maintained. The drag coefficient increases with wind speed up to moderate speeds, once the rough flow regime

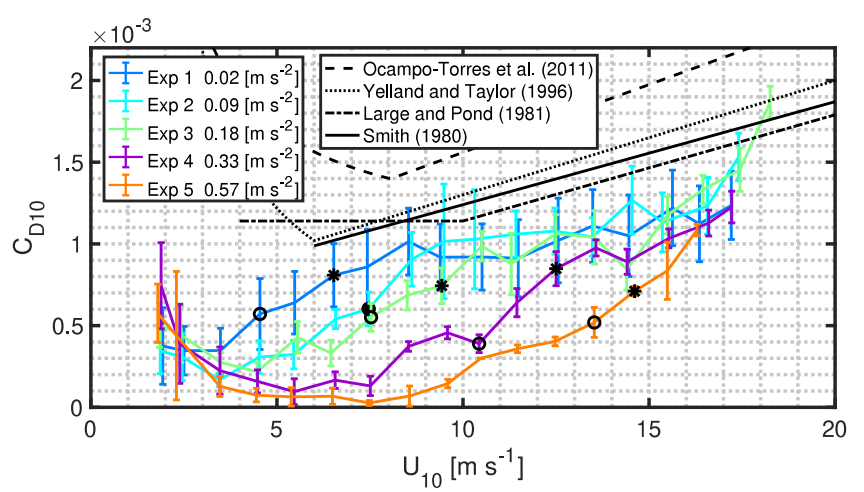

Fig. 8. Drag coefficient as a function of $10 \mathrm{~m}$ reference wind speed. The circle (o) and the asterisk ( $*$ ) indicates the value of encounter of $C_{D_{10}}$ for both, the limit for smooth flow regime and the threshold to reach a fully rough flow regime in each experiment, respectively.

Table 2

Drag coefficient associated with the limit for smooth flow regime $\left(R e_{*}<0.13\right)$, the rough flow regime threshold $\left(R e_{*}>2.2\right)$ and the limit $z_{f}=z_{0}$, for each experiment.

\begin{tabular}{llll}
\hline Exp. & $C_{D 10_{\text {tran. }}}$ & $C_{D_{10 z_{f}=z_{0}}}$ & $C_{D_{10_{\text {rough }}}}$ \\
\hline 1 & 0.00057 & 0.00077 & 0.00081 \\
2 & 0.00060 & 0.00079 & 0.00060 \\
3 & 0.00055 & 0.00072 & 0.00074 \\
4 & 0.00039 & 0.00074 & 0.00085 \\
5 & 0.00052 & 0.00072 & 0.00071 \\
\hline
\end{tabular}

is reached. A rather lower rate of change in $C_{D_{10}}$ is observed for wind speeds within the interval of $8.5 \mathrm{~m} \mathrm{~s}^{-1}<U_{10}<15.5 \mathrm{~m} \mathrm{~s}^{-1}$, $9.5 \mathrm{~m} \mathrm{~s}^{-1}<U_{10}<13.5 \mathrm{~m} \mathrm{~s}^{-1}, 10.5 \mathrm{~m} \mathrm{~s}^{-1}<U_{10}<14.5 \mathrm{~m} \mathrm{~s}^{-1}$, and $13.5 \mathrm{~m} \mathrm{~s}^{-1}<U_{10}<14.5 \mathrm{~m} \mathrm{~s}^{-1}$ for experiments $1,2,3$, and 4 respectively. This represents an almost constant $C_{D_{10}}$, and even somehow decreasing values are identified. The lower the wind acceleration, the wider the velocity range within this low rate change is observed. At higher wind speeds, the drag coefficient increases further with wind speed, more markedly for the low wind acceleration experiments $(1,2$, and 3$)$.

The lower the wind acceleration, the higher the $C_{D_{10}}$ value associated with certain wind speed. This relation is remarkable within the characteristic wind speed interval $4 \mathrm{~m} \mathrm{~s}^{-1}<U_{10}<10$ $\mathrm{m} \mathrm{s}^{-1}$. However, due to the low rate changes of $C_{\mathrm{D}_{10}}$ with $U_{10}$ observed under rough flow regime, the differences of $C_{D_{10}}$ values between experiments are reduced as wind speed increases. Thus, the drag coefficient associated with wind speeds higher than 15 $\mathrm{m} \mathrm{s}^{-1}$ is similar between experiments. Also, the experiment with the lowest acceleration (experiment 1) presents higher $C_{D_{10}}$ for lower wind speeds, but it does not reach the maximum $C_{D_{10}}$ associated with the maximum wind speed. The maximum value of $C_{D_{10}}$ is reached in experiment 3 . This fact suggests that the evolution of the surface roughness, i.e., incipient wave field, may change the tendency of $C_{D_{10}}$ with $U_{10}$.

Results from previous studies on drag coefficient behaviour are also included in Fig. 8 [3-6], as reference. During the experiments under accelerated wind conditions, drag coefficient values are always lower than those reported in the reference studies. It is certainly not expected to find a similar behaviour of drag coefficient to those given by the reference parametrizations, mainly because the state of development of the air boundary layer and the wave field are different under accelerated wind conditions. The reference parametrizations were obtained from conditions where the wave field has already reached the equilibrium with a local and uniform wind field. For the given accelerated wind conditions, the observed differences could be due to the fact that 
turbulent boundary layer is still under development. As it was observed in Fig. 6, given a certain wind speed, the associated turbulence level is higher as the wind acceleration is reduced (experiments 1, 2 and 3), i.e., the turbulent boundary layer is thicker, and therefore, the turbulent fluctuations may be higher than those present when wind acceleration is higher (experiments 4 and 5). Furthermore, low acceleration experiments show the presence of a thinner viscous layer that also could induce higher turbulent fluctuations. These differences on the magnitude of turbulent fluctuation due to the thickness of the boundary layer could be the reason for the differences between our results and the reference parametrizations. Under constant wind conditions, the boundary layer reaches its full state of development for all experiments, and the $C_{D_{10}}$ values get similar to the parametrizations. Even so, the drag coefficients reached for the highest wind speed are similar to some of the previous studies. Besides, in the range $7 \mathrm{~m} \mathrm{~s}^{-1}<U_{10}<13 \mathrm{~m} \mathrm{~s}^{-1}, C_{\mathrm{D}_{10}}$ from the lowest acceleration experiment are similar or slightly lower than some of those results reported by [4-6]. Hence, the higher the wind acceleration, the smaller the $C_{D_{10}}$ as compared with the values reported in previous studies. Under accelerated wind conditions, the $C_{\mathrm{D}_{10}}$ varies depending on the wind acceleration and the evolution of the surface roughness.

\section{Surface waves}

\subsection{Non-dimensional wave growth}

Non-dimensional wave energy, $\epsilon$, dominant wave frequency, $\nu$, and fetch, $\chi,[12,28]$ are given by:

$$
\begin{aligned}
& \epsilon=\eta^{2} \frac{g^{2}}{u_{*}^{4}} \\
& v=f_{p} \frac{u_{*}}{g} \\
& \chi=X \frac{g}{u_{*}^{2}}
\end{aligned}
$$

where $f_{p}$ is the spectral peak frequency, $X$ is the fetch, and $g$ is the gravity acceleration.

Results of non-dimensional energy, and non-dimensional frequency are shown as a function of non-dimensional fetch in Figs. 9 and 10, respectively. These data are from station 7, where wave and wind measurements were made simultaneously. Thus, the dimensional fetch, $X$, is constant; however, due to the variation of friction velocity under accelerated wind conditions, variations of non-dimensional fetch are encountered, accordingly. The non-dimensional fetch for this data set covers the range $10^{2}<$ $\chi<10^{5}$. The data were averaged in logarithmically spaced bands to obtain the mean tendency. Wave growth curves derived from field data [12] and laboratory experiments [13] are also included in Figs. 9 and 10, as reference. These growth curves represent the dependence of wave energy and peak frequency with fetch, typically under stationary conditions and with an equilibrium between surface waves and assumed constant wind speed.

Higher values of the non-dimensional energy associated with the shortest non-dimensional fetches in all the experiments are observed, when compared to [13] results, except for experiment 5 (Fig. 9). As $\chi$ increases, the observed $\epsilon$ values get more similar to [13] results, and in some cases they are even smaller depending on the experiment. From experiment 1 , it is observed that nondimensional energy increases with non-dimensional fetch. This experiment presents a similar tendency as [13]; however, with higher non-dimensional energy associated with a specific value of non-dimensional fetch. Results from experiments 2,3 , and 4 , suggest a rather constant behaviour of $\epsilon$ for certain range of $\chi$ values, resembling a non-dimensional energy saturation level. $\epsilon$
Table 3

Non dimensional $X, \epsilon$ and $v$ values associated with the limit for smooth flow regime $\left(R e_{*}<0.13\right)$ and the threshold to reach rough flow regime $\left(R e_{*}>2.2\right)$ for each experiment.

\begin{tabular}{lrlllll}
\hline Exp. & $\chi_{U_{10_{\text {tran. }}}}$ & $\epsilon_{U_{10_{\text {tran. }}}}$ & $v_{U_{10_{\text {tran. }} .}}$ & $\chi_{U_{10 \text { rough }}}$ & $\epsilon_{U_{10_{\text {rough }}}}$ & $v_{U_{10_{\text {rough }}}}$ \\
\hline 1 & 25187 & 42.61 & 0.05 & 6842 & 68.59 & 0.06 \\
2 & 6507 & 6.32 & 0.09 & 3852 & 2.33 & 0.11 \\
3 & 5406 & 0.65 & 0.11 & 2636 & 0.83 & 0.14 \\
4 & 3556 & 0.45 & 0.15 & 1715 & 0.24 & 0.21 \\
5 & 2067 & 0.29 & 0.20 & 1223 & 0.15 & 0.24 \\
\hline
\end{tabular}

values from experiment 5 distinctively show a similar tendency with $\chi$, as [13] but with smaller non-dimensional energy associated with a specific value of $\chi$. Therefore, it seems that the higher the wind acceleration, the less effective the wave growth is with the increase of the fetch.

While fetch is constant at measuring station 7 (as well as gravity), Fig. 9 provides us with an insight into the relation between friction velocity and energy. This shows how the behaviour of wave growth effectiveness as wind speed and friction velocity varies at a fixed location. In this case, increasing non-dimensional energy is directly linked to the relation between $\eta$ and $u_{*}$, while increasing non-dimensional fetch is directly linked to reducing $u_{*}$. The magenta and grey lines mark the $\chi$ values of encounter to match the threshold for rough flow regime and to reach the limit for smooth flow regime, respectively (values also shown in Table 3). They were determined through $u_{*}$ associated with $\operatorname{Re}_{*}$ values shown in Table 1.

For a given value of friction velocity, the higher the wind acceleration, the lower the wave energy, i.e., the lesser the wave field efficiency to grow upon a particular available momentum (a specific value of $u_{*}$ ). A characteristic tendency of $\eta$ as a function of $u_{*}$ is clearly observed in Fig. 9, distinctively under rough and smooth flow regimes in all experiments. It is readily apparent a rather different dependence of the energy on $u_{*}$ (or $\chi$ ) in each experiment. The change in behaviour occurs under different $u_{*}$ (or $\chi$ ) conditions, depending on the wind acceleration. Under rough flow conditions and relatively high values of $u_{*}$ (it can also be considered as the association of $\eta$ with $u_{*}$ ), it seems that the steepness of the relation between $\epsilon$ and $\chi$ is very similar to those results reported by [13]. On the other hand, under the smooth flow regime, this relation shows a relatively lower steepness in all experiments. The different behaviour of the relation of $\eta$ and $u_{*}$, can be associated with a relatively different efficiency of the surface waves to grow or to capture momentum from the amount available. The character change of $\eta$ and $u_{*}$ relation occurs under different $u_{*}$ conditions depending on the wind acceleration. The higher the wind acceleration, the higher the $u_{*}$ when this character change occurs. In all experiments, the energy associated with the highest $u_{*}$ values was higher than those results reported by [13], except in experiment 5 .

The non-dimensional peak frequency decreases as dimensionless fetch increases in all experiments (Fig. 10). The frequency downshift rates are close to the laboratory downshift rates measured by [13]. This frequency downshift due to non-linear wavewave interactions combined with air-sea transfers, is well described by [29]. The higher the wind acceleration, the higher the non-dimensional frequency; indicating that the wave field associated with higher acceleration experiments is less developed for a certain $\chi$ (Fig. 10). It is observed in all experiments that, as $\chi$ increases $v$ decreases with a similar tendency as reported by [13]. However, it seems that $v$ remains constant for some values of $\chi$, as $\chi$ increases. This behaviour seems to be in apparent association with the shorter fetches in experiments 2,3 and 4 . This $v$ tendency change, together with the $\epsilon$ behaviour, indicate that the wave growth is not as effective when $\chi$ increases, at least for 


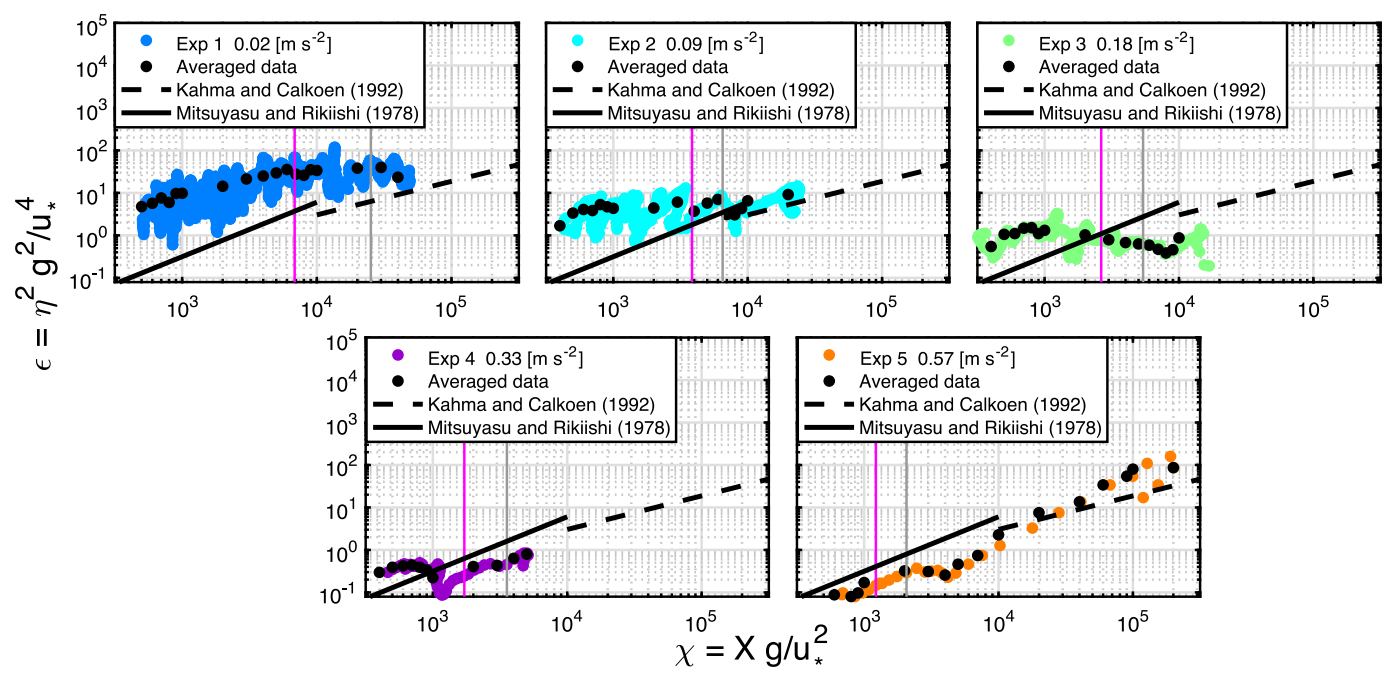

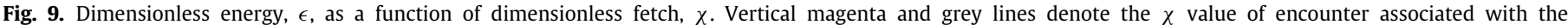

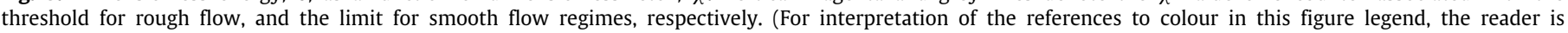
referred to the web version of this article.)

the highest acceleration experiments. For these experiments, as $\chi$ increases $v$ decreases, however the level of the [13] curve is not reached. Then, the energy saturation observed under increasing fetch, as shown in Fig. 9, is associated with a larger fetch required to properly observe the frequency downshift process, which is a characteristic linked to a more developed wave field.

The relation of $f_{p}$ and $u_{*}$ at station 7 (see Fig. 10) follows a similar pattern as the results reported by [13]. As it is shown in Fig. 9, in Fig. 10 it is also observed that the higher the wind acceleration, the higher the $u_{*}$ value associated with the tendency change observed in $v$ as a function of $\chi$. However, this $u_{*}$ value shows no direct association with the flow regime; nevertheless, it does depend on the wind acceleration. Associated with relatively low and high values of $u_{*}$, a specific variation of $v$ with $\chi$, might indicate a slight decrease of $f_{p}$ with $u_{*}$. However, under moderated $u_{*}$ values, $v$ is relatively constant, therefore $f_{p}$ decreases with $u_{*}$ in a stronger manner, i.e., a remarkable frequency downshift process is observed under this range of $u_{*}$ values. Furthermore, a greater wave growth efficiency was observed in this same range of $u_{*}$ values (see Fig. 9). Even if the frequency downshift process is observed, it is only in experiments 1 and 2 where fully developed wave field characteristics (such us low $f_{p}$ values) are observed for relatively high values of $u_{*}$. These results are in fair agreement with those reported by [13].

Although this analysis is performed to data obtained at station 7, it provides an idea of how the non-dimensional energy and frequency behave in association with non-dimensional fetch under accelerated wind conditions. It was observed that the spatial behaviour of $\epsilon$ and $v$ is different from that observed under conditions of equilibrium between wind and surface waves. At the shortest fetches, a stronger energy injection is observed, in comparison to the results from [13]. However, the energy injection seems to be not so effective, and an energy saturation level is reached even if $\chi$ increases, especially under high wind acceleration experiments. Furthermore, under the high acceleration wind conditions, a larger fetch seems to be required for surface waves to reach a high level of development and to properly observe the $v$ downshift process.

Some parametrizations from previous results were included in Figs. 9 and 10, as reference. Differences were obviously expected between our data and the reference parametrizations mainly due to the accelerated wind conditions inducing the generation of a non-equilibrium-wind-wave system, rather different from the one associated with [12] and [13] results, where the waves reached a local equilibrium with a uniform wind. The general conclusion from these differences is that the transfer of available momentum from wind to waves is more efficient under accelerated wind conditions in comparison to constant wind conditions.

A relationship between the drag coefficient and the wave field development can be elucidated from the results shown in Figs. 8, 9, and 10. Under the specific conditions associated with the threshold for a rough flow, it is in experiment 1 that the highest wave energy and the lowest peak frequency are observed, suggesting that the wave field is more developed when the surface roughness imposes an effect on air turbulence. A more developed wave field, as observed in the lowest wind acceleration case, might induce a rather constant $C_{D_{10}}$ within a wider range of wind speeds, in comparison to the experiments with higher acceleration. Results from experiment 5 show the least developed wave field, and therefore there is not any wind speed range with a constant $C_{\mathrm{D}_{10}}$. The importance of considering the effect of the wave field on the estimation of the drag coefficient was already evidenced in previous studies (e.g., [9]). In [9], a relation of increasing $C_{\mathrm{D}}$ with the non-linear parameter $\mu$ (a parameter that combines the effect wave steepness and the relative water depth) was shown. However, the highest values of $C_{D}$ were associated with low values of $\mu$ (that belongs to low wave steepness). It was reported that intermittent blast might induce an increase of drag coefficient values, even at those values of low wave steepness. These results might well be considered as an evidence that the accelerated wind conditions could modify the drag coefficient behaviour. They could be related with the fact that in Fig. 8, associated to maximum wind speed, the experiments with an intermediate wind acceleration and lower wave steepness (not shown) present higher drag coefficient than low acceleration experiments.

Although there is not an equilibrium with the wind, a fast response is observed from the wave field upon the changes in the wind stress. However, this response may not be instantaneous. This is suggested from experiment 3 results, where the highest value of the drag coefficient is reached when the maximum wind speed attained (this occurs at the end of the wind acceleration period in the experimental run), and the associated non-dimensional energy has a relatively low value (compared to the lowest wind acceleration case, for instance). The highest nondimensional energy, regardless of wind speed, is observed in the 


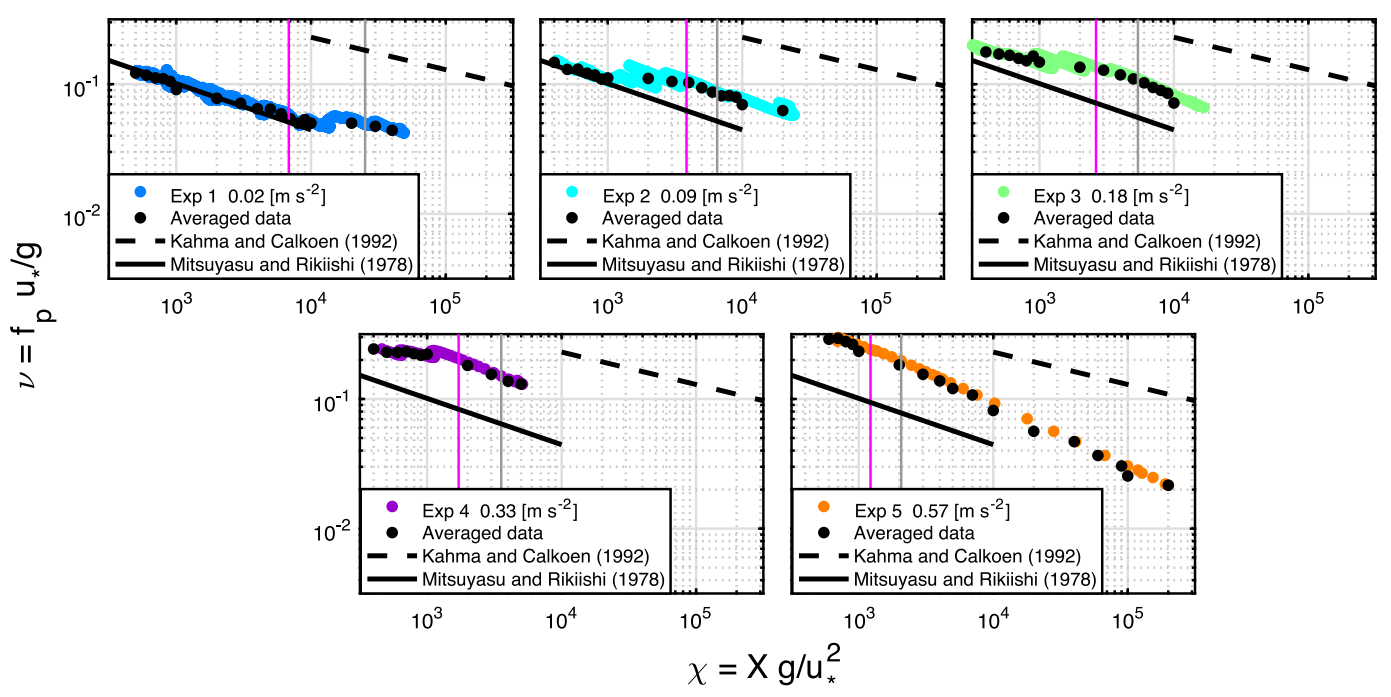

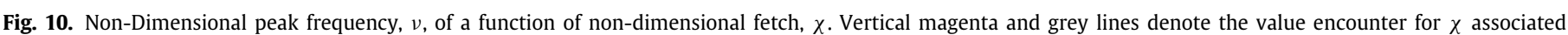

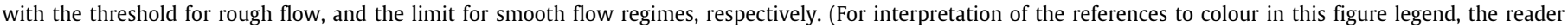
is referred to the web version of this article.)

results from experiment 1 , which is the one with the lowest wind acceleration.

\section{Summary}

From a laboratory set of experiments, the momentum transfer and the first stages of wind waves generation under accelerated winds were characterized. From high temporal resolution of air flow and surface displacement measurements, it was possible to estimate the turbulent fluctuations associated with the wind field and to establish some relations between the drag coefficient and the wave field. The effect of wind acceleration on the first stages of wave generation was also analysed.

It is determined that wind acceleration has a direct effect on the air boundary layer development. On the one hand, as wind acceleration increases the viscous sublayer thickness increases and the wave field energy decreases. On the other hand, as the wind increases the viscous sublayer becomes thinner. So a higher wind speed is needed to reach a rough flow regime as the acceleration increases between experiments. Therefore, under highly accelerated conditions, the effect of surface roughness on increasing air turbulence occurs at higher wind speeds. However, the fact that in an experiment with moderate acceleration (not the lowest) results show the highest values of turbulence associated with the maximum wind speed suggests that surface roughness and wave field play a significant role in the air turbulent boundary layer evolution under rough flow conditions.

Under smooth flow conditions, the drag coefficient decreases with wind speed. Under a rough flow regime, the drag coefficient typically increases with wind speed with a certain tendency, which is somehow reduced due to the influence of the roughness at the surface, especially when the wave field is more developed. In general, the higher the wind acceleration, the lower the drag coefficient. Furthermore, under high wind conditions, the drag coefficient values get very similar regardless the wind acceleration. For the particular experiment with moderate acceleration, the observed drag coefficient was the highest of all. These results indicate that the drag coefficient is not only dependent on wind speed, wind acceleration, and boundary layer development, but also the surface roughness plays an essential role in its evolution.

From the main characteristics of the wave field, and its relationship with some air boundary layer variables, the efficiency of wave growth under a certain value of $u_{*}$ can be depicted and also can be compared with data from laboratory experiments under constants wind conditions [13]. The wave growth efficiency increases as the wind acceleration decreases; it may be even higher than under constant wind conditions [13]. Under high accelerated wind conditions, the wave growth is less effective with wind speed and fetch increase. The $u_{*}$ value required to observe the peak frequency downshift process is higher for high acceleration experiments. This $u_{*}$ is independent from the flow regime.

From this study, it was possible to establish a relationship between momentum availability and wave growth efficiency. Under the smooth flow regime, the wind acceleration directly affects the turbulence generation and the magnitude of the drag coefficient. This fact implies that the amount of available momentum for wave generation is modified. However, under the rough flow regime, also the state of development of the wave field has a direct influence on drag coefficient behaviour with wind speed. A less developed wave field induces a higher increase in drag coefficient with wind speed. It was also observed that waves do not respond immediately to drag coefficient changes observed during rough flow conditions.

\section{Acknowledgements}

This work represents a contribution of RugDiSMar Project (CONACYT 155793), of CONACYT CB-2015-01 255377 Project, and the Mexican Research Consortium for the Gulf of Mexico Project (CIGoM), Mexico. Some part of this research work has been carried out within the framework of the Labex MEC. We express our gratitude to L.A. Julieta Castro for her administrative and logistic coordination support. Funding from Excellence Initiative of Aix-Marseille University - A*MIDEX, a French "Investissements d'Avenir" program, and from CONACYT-SENERHidrocarburos Project 201441, is greatly acknowledged. LR-D wishes to express her gratitude to CONACYT and the Physical Oceanography Department of CICESE, Mexico for the support provided as a PhD scholarship.

\section{References}

[1] M.A. Donelan, F.W. Dobson, S.D. Smith, R.J. Anderson, On the dependence of sea surface roughness on wave development, J. Phys. Oceanogr. 23 (1993) 2143-2149, http://dx.doi.org/10.1175/1520-0485(1995)025<1905: CODOSS $>2.0 . \mathrm{CO} ; 2$ 
[2] W.M. Drennan, On the wave age dependence of wind stress over pure wind seas, J. Geophys. Res. 108 (C3) (2003) 1-13, http://dx.doi.org/10.1029/ 2000JC000715.

[3] F.J. Ocampo-Torres, H. García-Nava, R. Durazo, P. Osuna, G.M. Díaz Méndez, H.C. Graber, The INTOA experiment: A study of ocean-atmosphere interactions under moderate to strong offshore winds and opposing swell conditions in the gulf of tehuantepec, Mexico, Bound.-Lay. Meteorol. 138 (3) (2011) 433-451, http://dx.doi.org/10.1007/s10546-010-9561-5.

[4] M. Yelland, P.K. Taylor, Wind stress measurements from the open ocean, J. Phys. Oceanogr. 26 (4) (1996) 541-558, http://dx.doi.org/10.1175/15200485(1996)026<0541:WSMFTO>2.0.CO;2.

[5] W.G. Large, S. Pond, Open ocean momentum flux measurements in moderate to strong winds, J. Phys. Oceanogr. 11 (3) (1981) 324-336, http://dx.doi.org/10.1175/1520-0485(1981)011<0324:OOMFMI>2.0.CO;2.

[6] S.D. Smith, Wind stress and heat flux over the ocean in gale force winds, J. Phys. Oceanogr. 10 (5) (1980) 709-726, http://dx.doi.org/10.1175/15200485(1980)010<0709:WSAHFO>2.0.CO;2.

[7] A.V. Babanin, V.K. Makin, Effects of wind trend and gustiness on the sea drag: Lake george study, J. Geophys. Res. 113 (2008) 1-18, http: //dx.doi.org/10.1029/2007JC004233, c02015

[8] S.D. Smith, R.J. Anderson, W.A. Oost, C. Kraan, N. Maat, J. DeCosmo, K.B. Katsaros, K.L. Davidson, K. Bumke, L. Hasse, H.M. Chadwick, Sea surface wind stress and drag coefficients: The hexos results, Bound.-Lay. Meteorol. 60 (1992) 109-142, http://dx.doi.org/10.1007/BF00122064.

[9] A. Toffoli, L. Loffredo, P. Le Roy, J.-M. Lefèvre, A.V. Babanin, On the variability of sea drag in finite water depth, J. Geophys. Res.: Oceans 117 (C00J25) (2012) http://dx.doi.org/10.1029/2011JC007857.

[10] I. Jones, Y. Toba, Wind Stress Over the Ocean, Cambridge University Press, 2001, p. 307

[11] E.L. Andreas, L. Mahrt, D. Vickers, An improved bulk air-sea surface flux algorithm, including spray-mediated transfer, Q. J. R. Meteorol. Soc. 141 (687) (2014) 642-654, http://dx.doi.org/10.1002/qj.2424.

[12] K.K. Kahma, C.J. Calkoen, Reconciling discrepancies in the observed growth of wind-generated waves, J. Phys. Oceanogr. 22 (12) (1992) 1389-1405, http://dx.doi.org/10.1175/1520-0485(1992)022<1389:RDITOG>2.0.CO;2.

[13] H. Mitsuyasu, K. Rikiishi, The growth of duration-limited wind waves, J. Fluid Mech. 85 (04) (1978) 705-730, http://dx.doi.org/10.1017/ S0022112078000889.

[14] Y. Toba, Local balance in the air-sea boundary processes I. On the growth process of wind waves, J. Oceanogr. Soc. Japan 28 (1972) 109-121.
[15] A. Masuda, T. Kusaba, On the local equilibrium of winds and wind-waves in relation to surface drag, J. Oceanogr. Soc. Japan 43 (1987) 28-36, http://dx.doi.org/10.1007/BF02110631.

[16] A. Toffoli, D. Proment, H. Salman, J. Monbaliu, F. Frascoli, M. Dafilis, E. Stramignoni, R. Forza, M. Manfrin, M. Onorato, Wind generated rogue waves in an annular wave flume, Phys. Rev. Lett. 118 (2017) 144503 http://dx.doi.org/10.1103/PhysRevLett.118.144503.

[17] H. García-Nava, F.J. Ocampo-Torres, P.a. Hwang, On the parameterization of the drag coefficient in mixed seas, Sci. Mar. 76 (S1) (2012) 177-186, http://dx.doi.org/10.3989/scimar.03615.19F.

[18] V. Guenard, P. Drobinski, J.-L. Caccia, B. Campistron, B. Bench, An observational study of the mesoscale mistral dynamics, Bound.-Lay. Meteorol. 115 (2) (2005) 263-288, http://dx.doi.org/10.1007/s10546-004-3406-z.

[19] B.M. Uz, M.A. Donelan, T. Hara, E.J. Bock, Laboratory studies of wind stress over surface waves, Bound.-Lay. Meteorol. 102 (2002) 301-331.

[20] T. Waseda, Y. Toba, M.P. Tulin, Adjustment of wind waves to sudden changes of wind speed, J. Oceanogr. 57 (2001) 519-533.

[21] M. Coantic, A. Ramamonjiarisoa, P. Mestayer, F. Resch, A. Favre, Windwater tunnel simulation of small-scale ocean-atmosphere interactions, J. Geophys. Res.: Oceans 86 (C7) (1981) 6607-6626, http://dx.doi.org/10. 1029/JC086iC07p06607.

[22] V.K. Makin, H. Branger, W.L. Peirson, J.P. Giovanangeli, Stress above windplus-paddle waves: Modeling of a laboratory experiment, J. Phys. Oceanogr. 37 (2007) 2824-2837, http://dx.doi.org/10.1175/2007JP03550.1.

[23] C.G. Lomas, Fundamentals of Hot Wire Anemometry, Cambridge University Press, 1986, p. 202.

[24] R.B. Stull (Ed.), An Introduction to Boundary Layer Meteorology, Springer Netherlands, 1988, http://dx.doi.org/10.1007/978-94-009-3027-8.

[25] H. Schlichting, K. Gersten, Boundary-Layer Theory, Springer Berlin Heidelberg, 2017, http://dx.doi.org/10.1007/978-3-662-52919-5.

[26] M. Raupach, R. Antonia, S. Rajagopalan, Rough-wall turbulent boundary layers, Appl. Mech. Rev. 44 (1) (1991) 1-25, http://dx.doi.org/10.1115/1. 3119492.

[27] J.R. Garratt, The Atmospheric Boundary Layer, Cambridge University Press, 1992, p. 316

[28] S.A. Kitaigorodskii, Applications of the theory of similarity to the analysis of wind-generated wave motion as a stochastic process, Izv. Akad. Nauk SSSR. Ser. Geofiz. 9 (1) (1962) 105-117, http://dx.doi.org/10.1016/00117471(62)90050-5.

[29] N.E. Huang, S.R. Long, Z. Shen, The mechanism for frequency downshift in nonlinear wave evolution, Adv. Appl. Mech. 32 (1996) 59 - 117C, http://dx.doi.org/10.1016/S0065-2156(08)70076-0. 